\title{
Characteristics of Homebirth in Hungary: a Comparative Retrospective Cohort Study
}

\author{
Girma Alemu Wami ( $\square$ girma.alemu.wami@etk.pte.hu ) \\ Doctoral School of Health Sciences, Faculty of Health Sciences, University of Pécs, Pécs, Hungary \\ Viktória Prémusz \\ Doctoral School of Health Sciences, Faculty of Health Sciences, University of Pécs, Pécs, Hungary \\ György M. Csákány \\ Department of Obstetrics and Gynecology, Jahn Ferenc Hospital, Köves út 1., H-1204 Budapest, Hungary \\ Kovács Kálmán \\ Department of Obstetrics and Gynecology, Faculty of Medicine, University of Pécs, Pécs, Hungary \\ Viola Vértes \\ Department of Obstetrics and Gynecology, Faculty of Medicine, University of Pécs, Pécs, Hungary \\ Péter Tamás \\ Department of Obstetrics and Gynecology, Faculty of Medicine, University of Pécs, Pécs, Hungary
}

Research Article

Keywords: home childbirth, institutional childbirth, mode of birth, perinatal mortality, pregnancy outcome

Posted Date: March 2nd, 2022

DOI: https://doi.org/10.21203/rs.3.rs-1388434/v1

License: (c) (i) This work is licensed under a Creative Commons Attribution 4.0 International License. Read Full License 


\section{Abstract \\ Background}

Births can take place either at home or in healthcare institutions in Hungary. Until 2012, home birth was neither legal nor illegal. But as of today, home birth is legal and regulated by law in Hungary, however, it has not yet been broadly accepted since only criminal cases were reported in the media before 2012. Our study aimed at exploring both real maternal and foeto-neonatal characteristics associated with Hungarian home births compared with institutional births.

\section{Methods}

A total of 2,997 cases were considered in support of our comparative retrospective cohort study. Data regarding home birth cases $(n=1792$ for years 2012-2020) was sourced from Hungarian Tauffer databases (2012-2020) and compared with its matched institutional birth data ( $\mathrm{n}=1205$ for the year 2020) obtained from a university linked obstetrical department. Both descriptive and inferential statistics were conducted.

\section{Results}

In the examined period, there was a significant, continual incremental rise in the number of home births from 0.04 (2012) to $0.48 \%$ (2020) in Hungary, which represent a cc of $0.22 \%$ per year $(95 \% \mathrm{Cl}, 0.02-0.25)$. The maternal age was $33.16 \pm 4.71$ and $29.69 \pm 5.44$ years for home births and institutionalized births, respectively $(p<.001)$. Mothers choosing homebirth were multiparous and the majority have experienced spontaneous mode of childbirth compared with mothers who gave birth at a health care institution $(p<.001)$. Some pathology (secondary uterine inertia, prolonged second stage labour and primary post-partum haemorrhage) were prevalent among homebirth cases $(p<.05)$; and associated with a cc. $12 \%$ rate of transfer to a health care institution. But, the overall intervention rate was lower among homebirth $(0.11 \%$ vs $42.57 \%)$ compared to institutional birth cases ( $p$ $<.001)$. A slightly better Apgar score among institutionalized newborns correlated with a relatively high rate $(20 \%)$ in Caesarean deliveries $(p<.05)$.

\section{Conclusions}

The finding of our study demonstrates an increasing number of home births in Hungary. Strict criteria and requirements for midwives of homebirth provide an acceptable alternative in support of home childbirth for relatively healthy, low-risk mothers, even if it is not entirely free of charge.

\section{Background}

Homebirth performed comprised of a licenced and registered midwife is a safe option for healthy, low-risk females $(1,2)$. Despite this premise, females who choose unregulated birth staff to support a home birth without the use of a registered midwife present is increasing (3). The safest place for a female to give birth to her baby is believed to be at a functional health facility including a professionally trained birth attendant. However, during the recent global crisis or due to other reasons, many females may result in giving birth at home (4). During the recent pandemic, many females felt detached from sexual and reproductive health services, due to quarantine protocols. Pregnant mothers were unwilling to come into their local health facilities due to disruptions in transportation associated with nationwide lockdown measures(5) while others shunned the hospital or clinic due to increased fear of the spread of infections (6). Hence, we noted a trend in soon-to-be mothers preferring to deliver their infants at home (7).

The World Health Organization (WHO) report has shown nearly 140 million females give birth annually, worldwide. Admittedly, it is not easy to predict the outcome of the pregnancy from its beginning whilst much is known regarding the clinical management of labour and childbirth, less attention is given to what clinical interventions make females feel safe, comfortable and positive regarding the experience in the birth of their babies (8). Women need to receive health care before and during pregnancy to decrease the risk of pregnancy complications (9). These problems can be caused by or can be made worse while being pregnant. Many problems are mild and do not progress; however, they may harm the mother and her newborn when they do. To cite a specific instance, birthweight which reflects intra-uterine growth retardation is an important determinant factor regarding perinatal morbidity and mortality $(10,11)$ and, in recent years, is a marker in identifying postnatal health risks (12).

In Hungary, home birth is legal and regulated by law since 2012. The law states, a female has the right to choose where to give birth, however, the law makes no provisions for individuals wishing to assist a birthing female beyond the hospital environment (13). Interestingly, home birth is not yet widely accepted, in reviewing criminal cases reported in the media before 2012 (14).

In Hungary, very little research has been published regarding home births for a multitude of reasons. However, outside of Hungary, several prosperous and high-income countries are considering the reintroduction of home births $(1,3)$. This is based on claims of equal safety at lower intervention rates compared to institutional births in which overtreatment may be present (15). Furthermore, it is based on the stated reduction of maternal-foetal morbidity and suggested psycho-social advantages for the mother (16). Thus, our study attempts to explore the real maternal and foeto-neonatal conditions and outcome characteristics regarding Hungarian home births as compared with institutional cases, which, contributes to the knowledge of 
midwives and pregnant mothers. It will benefit midwives to better understand and provide a level of care that is equally safe as institutional births at a lower intervention rate with an improved pregnancy outcome.

\section{Methods \\ Design and sample}

This study is a comparative retrospective cohort study. We sourced data regarding home births ( $n=1792$ from 2012 through 2020$)$ culled from a nationwide Hungarian obstetric registry, which also is referred to as the 'Tauffer database", and is a compulsory compiled Hungarian obstetric database (17). The 'Tauffer database' is managed and made available to researchers through the efforts of the National Institute for Quality and Organizational Development in Health Care and Medicine (reference 76/2004 ESzCsM, decree regarding the determination, collection and analysis of health-related unidentifiable data; Ministry of Health Social and Family Affairs, Hungary) (18) and an institutional birth data ( $\mathrm{n}=1205$ for the year 2020), which was sourced from a university-linked obstetrical department located in southern Hungary.

All mothers who willingly enrolled in this study were older than 18 years of age yet younger than 40 years old if it is their first pregnancy. Additional prerequisites included soon-to-be mothers within 37-41 weeks of gestation, a singleton pregnancy, the foetus in cephalic position, no prior history of any form of complication(s) during pregnancy and have access to a health facility that is equipped with obstetrical and neonatal services within 20 minutes travel time from the location of the planned birth, in the event, there is a need for assistance during the delivery. These were our criteria and are representative of the five basic permissive standards regarding home birth as stated in Hungarian fundamental Law (18).

Multiple pregnancies, a maternal age $<18$ and $\geq 40$ years, preterm birth ( $<37$ weeks of gestations), post-term birth ( $\geq 42$ weeks of gestations), noncephalic presentation and prior pathologic cases were excluded from our study since they were not considered a suitable candidate regarding home birth. Compulsory maternal, foetal and neonatal outcome conditions and complications, before and during pregnancy, were collected in full accordance to International Classifications of Diseases, 10th revision (ICD-10 codes) (19).

\section{Determinants}

Maternal determinants were of maternal age (younger age $(<35)$ and advanced age $(\geq 35)$ ), gestational age (term - 37 to 41 weeks), parity (Primi-para and multi-parous), previous abortion (one time and recurrent (>1)), mode of conception (Spontaneous and ART), rupture of membrane (SROM, tPROM and AROM) and mode of birth (SVB and OB).

Foeto-neonatal determinants included the gender of the newborn, stillbirth, Apgar score measured five minutes following birth, postnatal death at < 168 hrs, birth weight and birth weight percentiles. They were an independent variable, in which we have a dichotomous dependent variable (birthplaces i.e., home birth and institutional birth). Health care determinants included an intervention.

\section{Outcome measures}

Two primary outcomes were identified. First, intervention during birth. Intervention during birth is operational, defined as an intrapartum operative vaginal birth, and/or caesarean section and intrapartum artificial rapture of the membrane (AROM) represented as 'INTER2'. Secondly, perinatal mortality, in which it becomes operational, is a combination of stillbirths, intra-natal deaths, and early neonatal mortality until 168 hrs following delivery. The pooled outcome measures (Intervention* mortality case-mix) were used to determine the odds/risks among groups.

\section{Case-mix adjustment}

Studies addressing the benefits and drawbacks of home birth can be challenged due to their observational study design without case-mix adjustment regarding interventions and outcomes, the exclusion of females from the analysis, of which, according to standardized birth guidelines, should have been referred before birth.

The case-mix was represented by the prevalence of the "Big 4" conditions representative of an important risk mediator. The presence of these four conditions is known to precede $85 \%$ regarding perinatal mortality. These four-neonatal conditions are congenital abnormalities, Intra-uterine growth restriction (SGA, birth weight percentile $<10$, gender, and parity specific), preterm and Low Apgar score ( $<7$, measured $5 \mathrm{mins}$ following delivery) neonatal factors. In a system highlighted with optimal risk selection, "Big 4" conditions typically do not occur among low-risk mothers (16). However, since risk selection is not optimal in the Hungarian obstetric care system, "Big 2" conditions (intra-uterine growth restriction (small for gestational ageSGA) and low Apgar score) are still present in this group.

Case-mix adjustment is different regarding the intervention outcome (an intrapartum measurement) and mortality outcome (a postpartum measurement). When comparing mortality rates, the "Big 2" case-mix adjustment is used. However, when comparing intervention rates, the intervention precedes the outcome regarding a low Apgar score. Therefore, a low Apgar score should be excluded, and an analysis compiled. Then, intervention and perinatal mortality rate; adjusted for pooled prevalence (Intervention* mortality case-mix advanced model) were used to determine the odds /risks among groups.

\section{Data analysis}


The data were analysed using IBM SPSS statistics version 26. The excel datasets were cleaned and de-identified before exporting to SPSS. First, we compared the maternal characteristics, and then the foeto-neonatal birth characteristics by the planned location of delivery. Descriptive statistics using frequencies, percentages, means, and standard deviations all were generated. Data of continuous parametric variables were presented as a mean \pm standard deviation. Data of both dichotomous and polynomial categorical variables were presented using absolute values (n) and percentages (\%). The results of chi-square were presented in APA format (20).

In consideration of statistical analysis, we used logistic regression models. The presence of statistical associations and significant differences between maternal and foeto-neonatal birth characteristics and place of births were tested using a binary and multivariable logistic regression analysis model. Model 1, a binary logistic regression analysis, was presented as a crude odds ratio (COR), and Model 2, the multivariable logistic regression, after adjusting for the confounders, was presented as an adjusted odds ratio (AOR). In our study, a two-sided $P$ value $<.05$ was considered statistically significant at a $95 \%$ confidence interval. All the explanatory variables with a threshold of $p<.20$ on a binary logistic regression model were fitted to a multivariable regression model and adjusted for confounders. Statistical significance was also cross-checked using backwards and forward stepwise regression analysis and demonstrated the same statistical significance.

Third, we compared the perinatal mortality rates after the "Big 4" adjustment using an intention-to-treat-like approach. The intention-to-treat analysis is primarily used in RCT's (21). However, we used the 'intention-to-treat-like' analysis approach implies that all females having a home or institutional birth outcomes were included, independent from later referral during labour. In consideration of this analysis, a nested multiple stepwise regression model (stepwise analysis; inclusion $p<0.20$; exclusion $p>0.20$ ) was used (model 1 ).

Data transformation, recoding and categorization for several polynomial independent variables were made in variables with an observed count less than zero and were an insignificant fit regarding the model (determined using the Omnibus test for the model coefficient of $P<.05$, and Hosmer and Lemeshow goodness of fit for model at $P>.05$ ). Additionally, a pseudo-multicollinearity test (collinearity diagnostic) was performed before running multivariate logistic regression analysis to avoid high correlation among independent variables of maternal and foeto-neonatal birth characteristics, determined at variance inflation factor (VIF) of > 10 units and condition index > 30 units and interestingly, none of the variables was multicollinear.

\section{Operational definitions}

Assisted reproductive technologies (ART): defined as a mode of conception, either through in vitro-fertilization (IVF), hormonal or intrauterine insemination (IUI) (22).

At term, pre-labour rupture of membrane (tPROM): defined as a rupture in the membrane which occurs at term, either within or 24 hours before the onset of labour (23).

\section{Birth weight percentile (BWP)}

Birth weight percentile is calculated following the WHO recommended standards and using the Omni calculator available at https://www.omnicalculator.com/health/birthweight-percentile (24). The calculator considers the $50^{\text {th }}$ percentile as the average weight of the newborn at a specific age. Accordingly, the $50^{\text {th }}$ percentile at 37 weeks of gestations is $2781 \mathrm{~g}, 2961 \mathrm{~g}$ at 38 weeks, $3132 \mathrm{~g}$ at $39 \mathrm{weeks}, 3288 \mathrm{~g}$ at 40 weeks, and $3428 \mathrm{~g}$ at 41 weeks of gestation, respectively. Thus, the birth weight percentile classification is as follows:

1. Small for gestational age (SGA): A baby whose weight is less than $10^{\text {th }}$ percentiles

2. Appropriate for gestational age (AGA): A baby whose weight is between $10^{\text {th }}-90^{\text {th }}$ percentiles

3. Large for gestational age (LGA): A baby whose weight is more than $90^{\text {th }}$ percentiles

Foetal birth weight classifications

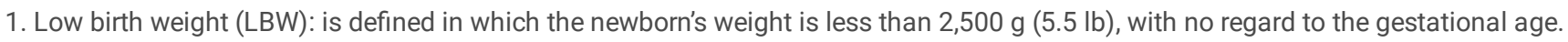

2. Normal/average/ birth weight (NBW): is defined in which the newborn's weight is between 2,500 and 4,000 g (5.5- $8.8 \mathrm{lb})$.

3. High birth weight (HBW): is defined in which the newborn's weight is more than or equals $4 \mathrm{~kg}(8.8 \mathrm{lb})(25)$.

Apgar scored at 5min:

A low Apgar score-is defined as a score less than seven (<7) when scores of all five indicators regarding the Apgar scoring system at five minutes (following birth) are combined. Unless it was considered as reassuring or a normal Apgar score $(\geq 7)(26,27)$.

Low-risk mother: defined as a female who is in relatively good health, has an uncomplicated medical and obstetric history (28), and when there is no factor in the family obstetric history (29).

Operative birth $(O B)$ : defined as an obstetric procedure that involves both operative vaginal birth and Caesarean sections to accomplish effective delivery (30). 
Operative vaginal births (OVB): defined when a childbirth process or a birth procedure involves episiotomy, the use of vacuum or forceps to accomplish birth (30).

Spontaneous vaginal Birth (SVB): defined as vaginal birth, occurring naturally and independent of any assistance (31).

Stillbirths: defined as a foetal intrauterine death following 24 weeks of gestation (17).

\section{Ethical approval}

This study received ethical approval including an assigned approval number, KK/608-1/2021, from the University of Pecs, Ethics Review Committee, and was conducted in full accordance with the Helsinki Declaration (32). All patient/client personal and medical data used for this study were handled in strict accordance with the European General Data Protection Regulation (GDPR), Act CXI of 2011 and Act XLVII of 1997 (33,34), and followed the decrees of the general authorization to process the personal medical data for scientific research purposes by the Hungarian Data Protection Authority (DPA) and the National Institute for Quality and Organizational Development in Health Care and Medicine (GYEMSZI) (35).

The study was also fully compliant with the data privacy protocol, according to Act CCIV, 2011, regarding the National Higher Education (HEA), Act CXII, of 2011, on the Right of Informational and Freedom of Information (Privacy Act), Act XLVII, of 1997, regarding the protection and processing of health data (Health Privacy Act), Regulation (EU) 2016/679 of the European Parliament and of the Council of 27 April 2016, regarding the protection of natural individuals and the processing of personal data and free movement of such data, including the repealing Directive 95/46/EC of GDPR, adopted by the Senate of University of Pécs (36).

\section{Results}

\section{Baseline characteristics of birthing women}

A total of 2997 females were included in our study. During the considered period, 1792 mothers who experienced home births were compared with 1205 mothers who experienced an institutionalized birth. Our data have shown, the prevalence of home births slowly increased over time by $2.23 \%$ per year $(95 \% \mathrm{Cl}, 0.02-0.25)$, on average (see figure 1$)$.

In consideration of home births, the mean maternal age at first delivery was $33.16 \pm 4.71$, were multiparous (55.9\%) and the majority experienced a spontaneous mode of childbirth (94.01\%), whereas $29.69 \pm 5.44$ regarding institutional births, $55.90 \%$ were primiparous and 888 (73.69\%) experienced spontaneous vaginal deliveries. The chi-square test of independence showed advanced age mothers ( $\geq 35$ years) were more likely to deliver at home compared with younger aged females $(<35), X^{2}(1, n=2997)=85.58, p<.001$. Notably, a mother who experienced a spontaneous mode of conception and had no prior history of previous abortions were more likely to experience homebirths $(p<.001)$, whereas nearly 332 (18.50\%) females who experienced home births, and 11(0.90\%) females who experienced institutional births used assisted reproductive technologies to conceive, $X^{2}(2$, $n=2997)=220.56, p<.001$ (see table 1$)$.

Table 1: Baseline characteristics of females who experienced home births and institutional births 


\begin{tabular}{|c|c|c|c|}
\hline & \multicolumn{2}{|c|}{ Place of birth } & \multirow{2}{*}{$\begin{array}{l}\mathrm{X}^{2} \text {-test of independence } \\
(\mathrm{n}=2997)\end{array}$} \\
\hline & $\begin{array}{c}\text { Home } \\
(\mathrm{n}=1792)\end{array}$ & $\begin{array}{l}\text { Institution } \\
(\mathrm{n}=1205)\end{array}$ & \\
\hline Maternal age (years) & $33.16 \pm 4.71 *$ & $29.69 \pm 5.44 *$ & $X^{2}(1)=85.58$ \\
\hline Younger age (18-34.99) & $1154(64.40 \%)$ & $965(80.10 \%)$ & $p<0.001$ \\
\hline Advanced age $(\geq 35)$ & $638(35.60 \%)$ & $240(19.90 \%)$ & $\square=0.17$ \\
\hline \multicolumn{4}{|l|}{ Parity } \\
\hline Primi-parous & $601(33.50 \%)$ & $674(55.90 \%)$ & $\begin{array}{r}X^{2}(1)=147.84 \\
p<0.001\end{array}$ \\
\hline Multiparous & 1191 (66.50\%) & $531(44.10 \%)$ & $\square=0.22$ \\
\hline \multicolumn{4}{|l|}{ History of abortion } \\
\hline No & 1561 (87.10\%) & $980(81.30 \%)$ & \multirow{3}{*}{$\begin{array}{r}X^{2}(2)=18.67 \\
p<0.001 \\
\square=0.08\end{array}$} \\
\hline One-time & $186(10.41 \%)$ & $181(15.01 \%)$ & \\
\hline Recurrent $(\geq 2 x)$ & $45(2.50 \%)$ & $44(3.70 \%)$ & \\
\hline \multicolumn{3}{|l|}{ Mode of conception } & \multirow{3}{*}{$\begin{array}{r}X^{2}(1)=220.56 \\
p<0.001 \\
\square=0.27\end{array}$} \\
\hline Spontaneous & $1460(81.50 \%)$ & 1194 (99.10\%) & \\
\hline ART & $332(18.50 \%)$ & $11(0.90 \%)$ & \\
\hline
\end{tabular}

$\left(^{*}\right)$ the result presented as a mean $S D, X^{2}(d f)$-Pearson-chi square (degree of freedom), and -is value of Cramer's $V$ (indicating measures of association). $\square=0$ depicts no association!

ART-Assisted Reproductive Technology

\section{Foeto-neonatal birth characteristics and outcome}

Of the total 2997 newborns, 1537 (51.30) were male, 1460 (48.70\%) were female, (99.89\%) were born alive, and 3 (0.11\%) were reported fatal cases (stillborn) during childbirth. The mean Apgar score at 5min was 9.87( \pm 0.61$)$ at home and $9.92( \pm 0.31)$ at institutions, respectively. Newborns from mothers who experienced home births had a slightly lower Apgar score at $5 \mathrm{~min}$ than when compared with institutional births $X^{2}(2, n=2997)=15.78$, $p<.001$ (see table 2).

The mean birth weight was slightly higher in-home births (3556.87 \pm 439.29$)$ and compared to institutional births $(3433.16 \pm 426.74), X^{2}(2, n=2997)$ $=22.34, p<.001$, of which, the majority were appropriate and large for gestational age $(59.01 \%, 39.5 \%)$ while few where small for gestational age $(1.50 \%)$ and they were below $10^{\text {th }}$ birth weight percentiles (see figure 2 ). Relatively high birth weight newborns were more likely born at home when compared with institutional deliveries, $X^{2}(2, n=2997)=22.34, p<.001$ (see table 2).

Of the five early neonatal deaths (<168hrs afterbirth), three $(0.20 \%)$ were from home and $2(0.17 \%)$ were among institutional births, and the reported stillbirths $(0.17 \%)$ and intranatal death at institution $(0.17 \%)$ were among transferred cases.

Table 2: Characteristics and outcomes of the newborns from mothers who experienced home birth and institutional births 


\begin{tabular}{|c|c|c|c|}
\hline & \multicolumn{2}{|c|}{ Place of birth } & \multirow{2}{*}{$\begin{array}{c}X^{2} \text {-test of } \\
\text { independence } \\
(n=2997)\end{array}$} \\
\hline & $\begin{array}{c}\text { Home } \\
(n=1792)\end{array}$ & $\begin{array}{l}\text { Institution } \\
(n=1205)\end{array}$ & \\
\hline Gender of the new-born & & & $X^{2}(1)=0.68$ \\
\hline Male & $908(50.70 \%)$ & $629(52.30 \%)$ & $p=0.411$ \\
\hline Female & $884(49.29 \%)$ & $576(47.79 \%)$ & $\varphi=0.02$ \\
\hline Apgar score (5mins) & $9.87( \pm 0.61)$ & $9.92( \pm 0.31)$ & $X^{2}(2)=15.78$ \\
\hline low $<7$ score & $27(1.50 \%)$ & $1(0.10 \%)$ & $p<0.05$ \\
\hline Normal $\geq 7$ score & $1746(97.43 \%)$ & $1200(99.60 \%)$ & $\varphi=0.07$ \\
\hline Missed value & $19(1.10 \%)$ & $4(0.30 \%)$ & \\
\hline \multicolumn{4}{|l|}{ Stillbirth } \\
\hline No & $1783(99.50 \%)$ & $1203(99.83 \%)$ & - \\
\hline Yes & $9(0.50 \%)$ & $2(0.17 \%)$ & \\
\hline \multicolumn{4}{|l|}{ Intra-natal death } \\
\hline No & $1791(99.94 \%)$ & $1203(99.83 \%)$ & - \\
\hline Yes & $1(0.06 \%)$ & $2(0.17 \%)$ & \\
\hline Birth weight (grams) & $3556.87 \pm 439.29$ & $3433.16 \pm 426.74$ & $X^{2}(2)=22.34$ \\
\hline Low birth weight & $6(0.30 \%)$ & $11(0.90 \%)$ & $p<0.001$ \\
\hline Average birth weight & $1503(83.90 \%)$ & $1070(88.80 \%)$ & $\varphi=0.09$ \\
\hline High birth weight & $283(15.80 \%)$ & $124(10.30 \%)$ & \\
\hline \multicolumn{4}{|l|}{ Birth weight percentile } \\
\hline SGA & $26(1.50 \%)$ & $37(3.10 \%)$ & $X^{2}(2)=40.34$ \\
\hline AGA & $1058(59.01 \%)$ & $818(67.90 \%)$ & $p<0.001$ \\
\hline LGA & $708(39.50 \%)$ & $350(29.01 \%)$ & $\varphi=0.12$ \\
\hline \multicolumn{4}{|l|}{ Early neonatal death $<168 \mathrm{hrs}$} \\
\hline No & $1789(99.80 \%)$ & $1203(99.83 \%)$ & - \\
\hline Yes & $3(0.20 \%)$ & $2(0.17 \%)$ & \\
\hline
\end{tabular}

(-) indicates unsuitable regarding the chi-square model and the expected count less than five is $>20 \%, X^{2}$ (df)-Pearson-chi square (degree of freedom), $\mathbb{X}$ -

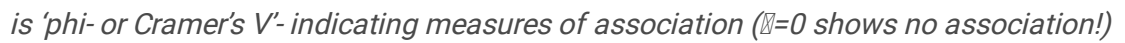

Acronym and abbreviations: AGA-Appropriate for gestational age (weight between $10^{\text {th }}-90^{\text {th }}$ percentiles), LGA-Large for gestational age ( $\geq 90^{\text {th }}$ percentiles) and SGA-Small for gestational age ( $<10^{\text {th }}$ percentiles).

\section{Maternal and foeto-neonatal birth outcome conditions and complications}

Of the total 2997 singleton births, 1183 (66.02\%) home births and 884 (73.36\%) institutional births were reported having no obstetric complications. A relatively higher number of mothers who experienced institutional births had prolonged first stage labour 40 (3.32\%), perineal laceration during birth (6.72\%), obstetric laceration of the cervix $(2.91 \%)$ and $35(2.91 \%)$ were anaemic $(P<.05)$ whereas a relatively higher number of foetal conditions including foetal acid-base imbalance 63(3.52\%), fetal heart rate anomaly and meconium-stained amniotic fluid 22 (1.23\%) were reported from home birth cases. Third stage haemorrhage delayed and secondary postpartum haemorrhage $(1.40 \%, 0.84 \%)$ were prevalent maternal conditions reported from home births (see table 3).

Table 3: Comparisons of maternal and foeto-neonatal home birth and institutional birth-related conditions and complications 


\begin{tabular}{lrr}
\hline & \multicolumn{2}{c}{ Place of birth } \\
\cline { 2 - 3 } Birth related conditions and complications (ICD-10) & $\begin{array}{c}\text { Home } \\
(\mathrm{n}=1792)\end{array}$ \\
\hline Non-obstetric complications ** & $1183(66.02 \%)$ & $884(73.36 \%)$ \\
Primary uterine inertia & $18(1.01 \%)$ & $5(0.41 \%)$ \\
\hline Prolonged first stage labour ** & $10(0.56 \%)$ & $40(3.32 \%)$ \\
\hline The prolonged second stage of labour* & $26(1.45 \%)$ & $20(1.66 \%)$ \\
\hline Obstructed labour due to incomplete rotation of the foetal head & $2(0.11 \%$ & $5(0.41 \%)$ \\
\hline Obstructed labour due to shoulder dystocia & $3(0.17 \%)$ & $8(0.66 \%)$ \\
\hline Obstructed labour due to foeto-pelvic disproportion & $3(0.17 \%)$ & $7(0.58 \%)$ \\
\hline Intrapartum hemorrhage (other) & $5(0.28 \%)$ & $2(0.17 \%)$ \\
\hline Fetal acid-base imbalance* & $63(3.52 \%)$ & $11(0.91 \%)$ \\
\hline FHR anomaly and meconium in the amniotic fluid & $22(1.23 \%)$ & $13(1.08 \%)$ \\
\hline First-degree perineal laceration during birth** & $59(3.29 \%)$ & $81(6.72 \%)$ \\
\hline Second-degree perineal laceration during birth* & $9(0.50 \%)$ & $14(1.16 \%)$ \\
\hline Third-degree perineal laceration during birth & $9(0.50 \%)$ & $7(0.58 \%)$ \\
\hline perineal laceration during birth (Unspecified) & $8(0.47 \%)$ & $6(0.50 \%)$ \\
\hline Obstetric laceration of the cervix & $5(0.28 \%)$ & $35(2.91 \%)$ \\
\hline Third stage haemorrhage** & $25(1.40 \%)$ & $12(0.10 \%)$ \\
\hline Delayed and secondary postpartum haemorrhage & $15(0.84 \%)$ & $5(0.41 \%)$ \\
\hline Retained placenta without haemorrhage & $3(0.18 \%)$ & $7(0.58 \%)$ \\
\hline Anaemia** & $10(0.56 \%)$ & $35(2.91 \%)$ \\
\hline
\end{tabular}

ICD-10 codes with frequency $(n<5)$ both at home and institution were not reported.

FHR- Fetal heart rate

${ }^{*} p$ value $<0.05$

** $p$ value $<0.01$

*** $p$ value $<0.001$

\section{Intervention rates}

Interventions were less prevalent among home births $(0.11 \%)$ compared with institutional births $(42.57 \%)(p<.001)$. The crude intervention risk ratio was significantly lower for females who experienced home births (COR 0.02, [95\% Cl 0.01-0.06, $P<.001]$ compared with females who experienced institutional births (Table 4, model 1). All maternal and neonatal risk factors (except the presence of a history of abortion, mode of birth and ROM), showed a significant difference. The adjusted intervention risk ratio demonstrates the birthplace indeed has a significant effect on the likelihood of intervention (AOR 0.02, [95\%Cl 0.01-0.05, P<.001) (Table 4, model 2).

\section{Perinatal mortality}

Perinatal mortality was relatively higher among home births, $11(0.61 \%)$, compared with institutional births. $6(0.49 \%)$, however, has not demonstrated any significant association with birthplace (see table 4).

Table 4: Summary statistics of women and feto-neonatal home and institutional birth characteristics and outcomes: pooled risk measures [Intervention (Mode of birth and AROM) and Perinatal mortality]; using intention-to-treat-like approach and case mix adjustment 


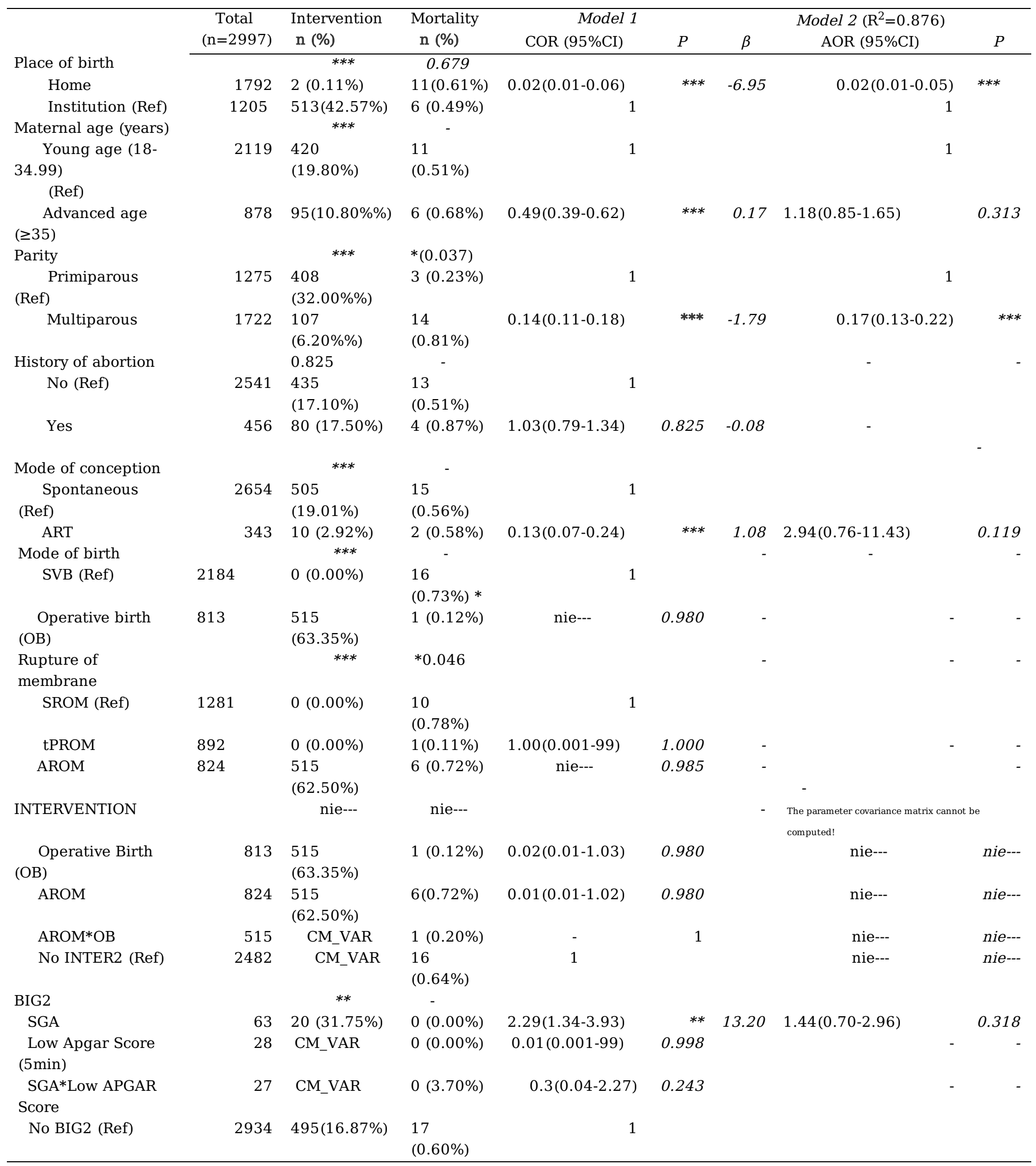

Variable(s) entered on step 1: Maternal age, Parity, History of Abortion, Mode of Conception 2, Intervention, BIG2 Mortality, Place of birth, and pooled outcome measures (Intervention*mortality).

$\mathrm{R}^{2}$-Nagelkerke R-square, $\beta$ - Regression coefficient, (-) indicates not fit (N/A) for the model, (nie---) indicates not computed for the model i.e. not indicated for enumeration(nie), and CM_VAR-variable(s) adjusted for the case-mixed Analysis i.e. Case-mix variable.

Abbreviations and acronyms: AROM-Artificial rupture of membrane, ART-Assisted Reproductive Technologies, OB-Operative birth, SGASmall for gestational age, Ref-reference group, SROM- spontaneous rupture of membrane (at term), SVB-Spontaneous vaginal birth, and tPROM- At term pre-labour rupture of membrane.

Variables at $\mathrm{p}<0.20$ fixed value threshold on binary logistic were fitted to the multivariable logistic regression model.

Model 1: Crude odds ratio 
Model 2: Adjusted for maternal and neonatal factors.

$* p<0.05$

$* * P<0.01$

$* * * P<0.001$

\section{Other determinants}

Only 24 (1.34\%) of females who experienced home births had an intention to operative birth. The institutional birth data also showed nearly 317 (26.31\%) had an operative birth, of which 472 (39.20\%) underwent an episiotomy, 65 (5.40\%) underwent vacuum-assisted delivery and 252 (20.90\%) experienced Caesarean sections. The hospital Caesarean section rate hovers at $0.21(20.90 \%)$, and the operative birth rate is nearly 0.65 (65.40\%) regarding institutional deliveries.

On average, the institutional transfer rate was $11.77 \%$ and nearly $204(11.77 \%)$ out of a total number of 1792 females who experienced home births were transferred to a hospital. In the given period (2012-2020), nearly 397 out of $1792(26.15 \%)$ females were hospitalized soon thereafter, of which, 105 (26.45\%) underwent Caesarean sections. Nearly 12 (11.43\%) out of 105 females were hospitalized and many of these patients were primiparous females. Out of the total 601 females who gave birth for the first time at home, nearly 361 (60.06\%) were hospitalized and 21 out of 619 (3.39\%) females who experienced home births for the second time, $3.31 \%$ of 393 females who experienced for the third time and two out of 39 ( $5.10 \%$ ) females who experienced home birth five times were hospitalized (see figure 3 ).

\section{Discussion}

Our data has shown a growing phenomenon regarding home births over a current period in Hungary. The Hungarian home birth rate (0.22\%) is considerably low when compared with the Netherlands (17\%) (37), New Zealand (3.5\%) (38), Australia (0.3\%) (39) and the United Kingdom (2.4\%) (40). Studies have indicated homebirth choice is controversial and enshrouded in debate. Generally, issues related to risk and safety in a well-integrated health care system, home birth is also deemed safe for healthy, low-risk females. $(1,2)$

In Hungary, very little research has been published regarding home births for a multitude of reasons, specifically, the lack of funding and institutional support. However, beyond Hungary, studies indicate females who plan home births experience a very low risk of instrumental vaginal birth and Caesarean section, therefore, a higher probability of spontaneous vaginal birth (15,28,41-43). Distinctly, our study has shown the majority (64.3\%) of low-risk multiparous females experienced spontaneous deliveries at home and were less likely to undergo an operative birth ( $p<.001)$. A study originating from four Nordic countries in northern Europe have shown the majority of low-risk multiparous females who experienced spontaneous birth in their previous pregnancies were more likely to give birth at home (41), and low-risk pregnancies attended by qualified midwives ushered in positive results among both maternal and newborn health levels, including low rates of obstetric intervention $(28,42,43)$, similar to the investigation by GaleraBarbero \& Aguilera-Manrique (15).

Additionally, our study demonstrated how advanced age mothers (aged $\geq 35 y e a r s)$ were more likely to experience home births than when compared with younger age mothers $(p<.001)$. Our finding is consistent with the comparative study by Éva Beaujouan and Tomáš Sobotka, from the Austrian Institute of Demography, aptly substantiated a general indication in the increased number of late childbearing age to females aged 40 and above (44). The study by Landero et al (45) and Shan et al (46) also showed the mean maternal age experiencing their first delivery and over 35 years of age. Yet another study from Australia also showed an increased prevalence among older maternal age experiencing their first delivery (47). Today, it is becoming common for females in developed countries to delay their childbearing age. Older maternal age at first birth is now an ingrained demographic trend in higher-income countries. This phenomenon is due to multiple factors, yet effective birth control methods significantly contribute to postponing motherhood (44).

In our study, obstetrical conditions and complications related to mothers were prevalent among institutional births, while neonatal related pathologic conditions and complications were relatively more frequent among home birth cases $(p<.05)$. Interestingly, the systematic review from Denmark showed, low-risk mothers with no previous history of obstetric complications and outcome conditions were highly likely to experience planned home births than when compared with mothers with a previous history of either medical or obstetrical outcome conditions (48).

We found $1.5 \%$ of newborns from mothers who experienced home births had a relatively low Apgar score. Studies have shown, a newborn with a low Apgar score is relatively at a greater risk for obstetric and pregnancy-related complications (27), Bolten et.al (28), Galera-Barbero \& AguileraManrique (15) and Shan et al. (46). Additionally, our findings are consistent with a study by Chandra et.al regarding differences in maternal characteristics and pregnancy outcomes which has significantly shown an association between a low Apgar score at $5 \mathrm{mins}$ and poor pregnancy outcomes $(p<.05)(49)$.

In our study, a relatively higher number of females experienced prolonged second stage labour in which the hospital transfer rate was $11.77 \%$. A systematic review of a large number of studies have shown home birth with a transfer rate of $11.77 \%$ is considered reasonable, and an indication the system is well integrated and able to support an expectant mother's choice regarding the place of birth (50). A possible explanation implies females 
who planned home birth were considerably low risk throughout labour and less likely to be transferred to an institution for advanced obstetric care, which typically results in a prolonged duration in second stage labour (28). This condition again is associated with the use of episiotomy which also leads to perineal lacerations and intrapartum haemorrhage $(46,48)$. Similarly, our study also showed primary uterine inertia, third stage haemorrhage, delayed and secondary postpartum haemorrhage which, was reported from females who experienced home births. The other possible reasons why the duration of second stage labour was shorter regarding institutional births may be due to improved intervention rates (option for Caesarean sections and/or instrumental births) ( $p<.001)$ supplemented with continuous monitoring of maternal and fetal conditions during and following delivery. Additionally, our study showed "Big 2" pregnancies at home exhibit a mortality disadvantage, suggesting comparatively lower intervention rates. The occurrence of overtreatment in the institution may be present in the "Big 2" females. However, the benefit of substantially fewer interventions among the home birth group seems to be counterbalanced by substantially increased rates of mortality. However, our findings were partially inconsistent regarding the study from the Netherlands, in which increased larger sample sizes $(n=146,752)$ demonstrated planned home births attended by registered community midwives confirm the lower risk of medical intervention resulting in equal rates of mortality (37). Other possible explanations were due to increased chances for females who planned home birth to switch their birthplace to an institution due to a medical condition they recently experienced just before or during labour. Nonetheless, the safety and risks related to home birth is not well expounded upon and is very much a topic of debate. Available published literature also substantiates regional variability $(15,28,41,42,45,46,51)$.

\section{Strength}

Notably, case-mix adjustment resulted in the most important aspect and strengthened our study. We previously showed, among the low-risk group of midwives led deliveries, an unequal prevalence of "Big 2" conditions presents in the planned home versus institutional births. This suggests an unequal risk load at the onset of childbirth, either due to self-selection or due to the midwife's proposal, the healthiest and most affluent women are more likely to undertake a home birth. Without adjusting for this, one risks confounding the issue by indication bias.

\section{Limitations}

- Tauffer databases are compulsory databases, however, some outcome variables were missed and less likely to be compared.

- Apgar scores at one minute following delivery were not recorded in a compulsory database regarding home birth cases.

- Lack of information regarding maternal dropout and transfer for obstetric care, midwifery experiences, training and their practices implemented in monitoring and evaluating feto-maternal conditions before and during birth.

- Despite baseline matching about potential confounders and restriction to low-risk women in our study, the possibility of residual confounding cannot be excluded given an observational study.

\section{Conclusions}

If risk selection can be improved in terms of detection and timely referral, home births can be as safe as institutional births. In careful consideration regarding our findings, both maternal and fetal-neonatal outcome conditions were relatively better among institutional births when considering a comparatively lower perinatal mortality rate, however, it is backed by higher intervention rate. More research is needed referencing the precise clinical assessment leading to referral or intervention which will allow a better judgement since this difference may be observed due to less-or poor detection of risk groups. Midwives should be well-trained regarding strict clinical guidelines to precisely identify low-risk mothers and upon those conditions to pursue the immediate transfer to avoid avoidable complications. Moreover, detailed information (including statistical data) will help midwives and pregnant mothers to understand and choose their potential birthplaces resulting in improved pregnancy outcomes.

\section{List Of Abbreviations}

ART- Assisted Reproductive Technology

GBS- Group B streptococcus

MOI- Medical Ovulation Induction

PPH-Postpartum Haemorrhage

\section{Declarations}

\section{Acknowledgements}

We acknowledge Prof. Sára Jeges for her valuable contributions and technical assistance during data processing and analysis. We also wish to extend our appreciation to $\mathrm{Mr}$ Abraham Sahlemichael for his statistical advice and general contribution in support of our study.

\section{Authors contributions}


Substantial contributions toward conception and design, acquisition of data, analysis and interpretation of data are attributed to (G.A.W, V.P, G.M.C, K.K, V.V, P.T). Drafting, editing, and revising the article ensuring precise intellectual content is attributed to (G.A.W, V.P, K.K, P.T). All authors have read and approved the final manuscript.

\section{Funding}

This research was supported by the National Laboratory for Human Reproduction (HRNL) and by EFOP-3.6.3-VEKOP-16-2017-00009, the "Development of Scientific Workshops of Medical, Health Sciences and Pharmaceutical Education". The funding sources did not have a role in the study design, collection, analysis, and interpretation of data, or in writing and submitting this manuscript.

\section{Availability of data and materials}

Data which supports the findings of this study (Tauffer dataset) are available, however, certain restrictions apply regarding the availability of these data, which was used under license for the current study, and therefore, are not publicly available.

\section{Ethics approval and consent to participate}

This study received ethical approval and was assigned an approval number, KK/608-1/2021, from the University of Pecs, Ethics Review Committee. It was conducted in full accordance with the Helsinki Declaration, and it adhered to the mandates of the general authorization to process personal data for scientific research purposes by the Hungarian Data Protection Authority. The need for informed consent, according to national legislation, was waived by the IRB listed above, since this was a retrospective cohort study

\section{Consent for publication}

Not applicable

\section{Competing of interests}

The authors have no conflict of interest to declare.

\section{Authors' information}

${ }^{1}$ Doctoral School of Health Sciences, Faculty of Health Sciences, University of Pécs, Vörösmarty u. 4. H-7621 Pécs, Hungary. ${ }^{2}$ ELKH-PTE Human Reproduction Scientific Research Group, University of Pécs, Édesanyák u. 17. H-7624 Pécs, Hungary. ${ }^{3}$ Department of Obstetrics and Gynecology, Jahn Ferenc Hospital, Köves út 1., H-1204 Budapest, Hungary. ${ }^{4}$ Department of Obstetrics and Gynecology, Faculty of Medicine, University of Pécs, Édesanyák u. 17. H-7624 Pécs, Hungary.

\section{References}

1. Catling-Paull C, Foureur MJ, Homer CSE. Publicly-funded homebirth models in Australia. Women and Birth. 2012;25(4):152-8; doi: 10.1016/j.wombi.2011.10.003

2. Sassine H, Burns E, Ormsby S, Dahlen HG. Why do women choose homebirth in Australia? A national survey. Women and Birth. 2021;34(4):396404; doi: 10.1016/j.wombi.2020.06.005

3. Rigg EC, Schmied V, Peters K, Dahlen HG. A survey of women in Australia who choose the care of unregulated birthworkers for a birth at home. Women and Birth. 2020 Feb 1;33(1):86-96.

4. United Nations Children Fund. Maternal and newborn health and COVID-19 - UNICEF DATA. 2020 [cited 2021 Nov 23 ]. Available from: https://data.unicef.org/topic/maternal-health/covid-19/

5. UNICEF. Maternal and newborn health and COVID-19 - UNICEF DATA [Internet]. 2020 [cited 2022 Jan 11]. Available from: https://data.unicef.org/topic/maternal-health/covid-19/

6. Médecins Sans Frontières(MSF). Women face greater danger during coronavirus COVID-19 pandemic | MSF [Internet]. 2020 [cited 2022 Jan 11] Available from: https://www.msf.org/women-and-girls-face-greater-dangers-during-covid-19-pandemic 
7. de Freytas-Tamira K. Pregnant and Scared of 'Covid Hospitals,' They're Giving Birth at Home - The New York Times [Internet]. New York Times. 2020 [cited 2022 Jan 11]. Available from: https://www.nytimes.com/2020/04/21/nyregion/coronavirus-home-births.html

8. World Health Organization. Intrapartum care for a positive childbirth experience [Internet]. 2018. 212 p. Available from: http://apps.who.int/iris/bitstream/10665/260178/1/9789241550215-eng.pdf? ua=1\%0Ahttp://www.who.int/reproductivehealth/publications/intrapartum-care-guidelines/en/

9. Center for Disease Control and Prevention. Pregnancy Complications | Maternal and Infant Health | CDC [Internet]. Reproductive Health. 2018. Available from: https://www.cdc.gov/reproductivehealth/maternalinfanthealth/pregnancy-complications.html

10. Ilori IU, Ituen AM, Eyo CS. Factors associated with mortality in neonatal surgical emergencies in a developing tertiary hospital in Nigeria. Open $\mathrm{J}$ Pediatr. 2013;03(03):231-5.

11. Katz J, Lee ACC, Kozuki N, Lawn JE, Cousens S, Blencowe H, et al. Mortality risk in preterm and small-for-gestational-age infants in low-income and middle-income countries: A pooled country analysis. Lancet. 2013;382(9890):417-25.

12. Hanson MA, Gluckman PD. Early developmental conditioning of later health and disease: physiology or pathophysiology? Physiol Rev. 2014;94(4):1027-76.

13. Eggermont M. News \& Views: The choice of child delivery is a European human right. Eur J Health Law. 2012;19(3):257-69.

14. The Guardian. The right to a home birth in Hungary | Hungary | The Guardian [Internet]. 2010 [cited 2022 Jan 23]. Available from:

https://www.theguardian.com/world/2010/nov/09/home-birth-in-hungary

15. Galera-Barbero TM, Aguilera-Manrique G. Planned home birth in low-risk pregnancies in spain: A descriptive study. Int J Environ Res Public Health. 2021;18(7).

16. Kooy J, Birnie E, Denktas S, Steegers EAP, Bonsel GJ. Planned home compared with planned hospital births: Mode of delivery and Perinatal mortality rates, an observational study. BMC Pregnancy Childbirth. 2017 Jun 8;17(1):1-11.

17. Zsirai L, Csákány GM, Vargha P, Fülöp V, Tabák ÁG. Breech presentation: Its predictors and consequences. An analysis of the Hungarian Tauffer Obstetric Database (1996-2011). Acta Obstet Gynecol Scand. 2016;95(3):347-54.

18. WHO. Essential values and fundamental principles, Fundamental Law of Hungary. Law, Fundam Xx, Artic Cliv, Act Care, Heal. 2015;(April):1-44.

19. Revision I-10 ISC of D and RHP 10th. ICD-10-CM Codes for Pregnancy, childbirth and the puerperium [Internet]. 2021. Available from:

https://www.icd10data.com/ICD10CM/Codes/000-09A

20. Guidelines APAT. Part A: Reporting Results of Common Statistical Tests in APA Format. Statistics (Ber) [Internet]. 2010;5(33):1-8. Available from: http://www.ncbi.nlm.nih.gov/pubmed/22137395

21. Abraha I, Cherubini A, Cozzolino F, De Florio R, Luchetta ML, Rimland JM, et al. Deviation from intention to treat analysis in randomised trials and treatment effect estimates: meta-epidemiological study. BMJ. 2015 May 27;350.

22. Chapman C. Assisted reproductive technology. Lab Med. 1996;27(8):524-31.

23. Marowitz A, Jordan R. Midwifery Management of Prelabor Rupture of Membranes at Term. J Midwifery Women's Heal. 2007;52(3):199-206.

24. Miszewska D. Birth Weight Percentile Calculator [Internet]. 2021. Available from: https://www.omnicalculator.com/health/birthweight-percentile

25. World Health Organization (WHO). Birth Weight Classification. WHO [Internet]. 2011;2011. Available from:

http://media.mycme.com/documents/45/table_11_-_birth_weight_classi_11083.pdf

26. Hogan L, Ingemarsson I, Thorngren-Jerneck K, Herbst A. How often is a low 5-min Apgar score in term newborns due to asphyxia? Eur J Obstet Gynecol Reprod Biol. 2007;130(2):169-75.

27. Assunção Salustiano EM, DuarteBonini Campos JA, Ibidi SM, Ruano R, Zugaib M. Low Apgar scores at 5 minutes in a low risk population: Maternal and obstetrical factors and postnatal outcome. Rev Assoc Med Bras. 2012;58(5):587-93.

28. Bolten N, de Jonge A, Zwagerman E, Zwagerman P, Klomp T, Zwart JJ, et al. Effect of planned place of birth on obstetric interventions and maternal outcomes among low-risk women: A cohort study in the Netherlands. BMC Pregnancy Childbirth. 2016;16(1); doi:10.1186/s12884-016-11306 
29. Obstetrics $\mathrm{G}$ and ARS of the PC of H. Az Emberi Erőforrások Minisztériuma egészségügyi szakmai irányelv a családbarát alapelvekre épülő szülészeti és újszülött ellátásról [Ministry of Human Resources Health Professional Directive on obstetrics and neonatal care based on family-friendly princi. 2019;

30. Amos Grünebaum MD. Operative Procedures_ Forceps, Vacuum, Episiotomy_ babyMed [Internet]. 2020. Available from: https://www.babymed.com/labor-delivery/operative-procedures-pregnancy-forceps-vacuum-episiotomy\#

31. Patterson DA, Winslow M, Matus CD. Spontaneous vaginal delivery [Internet]. Vol. 78, American Family Physician. 2008. Available from: https://www.healthline.com/health/pregnancy/spontaneous-vaginal-delivery\#: :text=A spontaneous vaginal delivery is a vaginal delivery,occurs after a pregnant woman goes through labor.

32. Declaration T, Code I, Ethics M. Declaration of Helsinki ( 1964 ) Introduction I. Basic Principles. 1964;1-3.

33. European Commission. 2016/679 regulation (EU) of the European Parliament and of the Council on the protection of natural persons with regard to the processing of personal data and on the free movement of such data, and repealing Directive 95/46/EC. Off J Eur Union. 2018;2016(68):48-119.

34. NAlH. Act CXII of 2011 on the Right of Informational Self-Determination and on Freedom of Information. Nemzeti Adatvédelmi és Információszabadság Hatóság [Internet]. 2011;(5). Available from: http://www.naih.hu/files/Privacy_Act-CXII-of-2011_EN_201310.pdf

35. WHO. Essential values and fundamental principles, Fundamental Law of Hungary. 2015; Available from:

http://www.who.int/nmh/events/Member-State-Hungary.pdf?ua=1

36. Hungary NHE of. Data Protection Regulation of the University of Pécs. 2018;(May). Available from: https://e-egeszsegugy.gov.hu/web/eesztinformation-portal/data-protection

37. Kooy J, Birnie E, Denktas S, Steegers EAP, Bonsel GJ. Planned home compared with planned hospital births: Mode of delivery and Perinatal mortality rates, an observational study. BMC Pregnancy Childbirth. 2017 Jun 8 [cited 2022 Jan 18];17(1):1-11. Available from: https://bmcpregnancychildbirth.biomedcentral.com/articles/10.1186/s12884-017-1348-y

38. Ministry of Health NZ. Report on Maternity web tool | Ministry of Health NZ [Internet]. 2021 [cited 2022 Jan 18]. Available from: https://www.health.govt.nz/publication/report-maternity-web-tool

39. Australian Institute of Health and Welfare. Australia's mothers and babies 2018-in brief, Summary - Australian Institute of Health and Welfare [Internet]. 2020 [cited 2022 Jan 18]. Available from: https://www.aihw.gov.au/reports/mothers-babies/australias-mothers-and-babies-2018-inbrief/summary

40. Office for National Statistics. Birth characteristics in England and Wales: 2020 [Internet]. ONS. 2020 [cited 2022 Jan 18]. Available from: https://www.ons.gov.uk/peoplepopulationandcommunity/birthsdeathsandmarriages/livebirths/bulletins/birthcharacteristicsinenglandandwales/2020

41. Edqvist M, Blix E, Hegaard HK, Ólafsdottir OÁ, Hildingsson I, Ingversen K, et al. Perineal injuries and birth positions among 2992 women with a low risk pregnancy who opted for a homebirth. BMC Pregnancy Childbirth. 2016;16(1); doi: 10.1186/s12884-016-0990-0

42. De Jonge A, Mesman JAJM, Manniën J, Zwart JJ, Van Dillen J, Van Roosmalen J. Severe adverse maternal outcomes among low risk women with planned home versus hospital births in the Netherlands: Nationwide cohort study. BMJ. 2013;346(7914):1-10.

43. Christensen LF, Overgaard C. Are freestanding midwifery units a safe alternative to obstetric units for low-risk, primiparous childbirth? An analysis of effect differences by parity in a matched cohort study. BMC Pregnancy Childbirth. 2017;17(1):1-11; doi: 10.1186/s12884-016-1208-1

44. Beaujouan É, Sobotka T. Late childbearing continues to increase in developed countries. Popul Soc. 2019;(562):1-4.

45. Londero AP, Rossetti E, Pittini C, Cagnacci A, Driul L. Maternal age and the risk of adverse pregnancy outcomes: A retrospective cohort study. BMC Pregnancy Childbirth. 2019;19(1):1-10.

46. Shan D, Qiu PY, Wu YX, Chen Q, Li AL, Ramadoss S, et al. Pregnancy Outcomes in Women of Advanced Maternal Age: a Retrospective Cohort Study from China. Sci Rep. 2018;8(1):1-9.

47. McMahon CA, Boivin J, Gibson FL, Hammarberg K, Wynter K, Saunders D, et al. Age at first birth, mode of conception and psychological wellbeing in pregnancy: Findings from the parental age and transition to parenthood Australia (PATPA) study. Hum Reprod. 2011;26(6):1389-98.

48. Aldridge R, Naysmith L, Ee Ting O, Murray C, Jonathan L. Europe PMC Funders Group. Acta Derm Venereol. 2013;93(6).

49. Chandra I, Sun L. Third trimester preterm and term premature rupture of membranes: Is there any difference in maternal characteristics and pregnancy outcomes? J Chinese Med Assoc. 2017;80(10):657-61; doi: 10.1016/j.jcma.2016.12.006

Page $14 / 16$ 
50. Blix E, Kumle M, Kjærgaard H, Øian P, Lindgren HE. Transfer to hospital in planned home births: A systematic review. BMC Pregnancy Childbirth. 2014 May 29;14(1):1-11.

51. Fisher J, Wynter K, Hammarberg K, McBain J, Gibson F, Boivin J, et al. Age, mode of conception, health service use and pregnancy health: A prospective cohort study of Australian women. BMC Pregnancy Childbirth. 2013;13:1-13.

\section{Figures}

HOMEBIRTH PRACTICES BY YEAR IN HUNGARY (2012-2020)

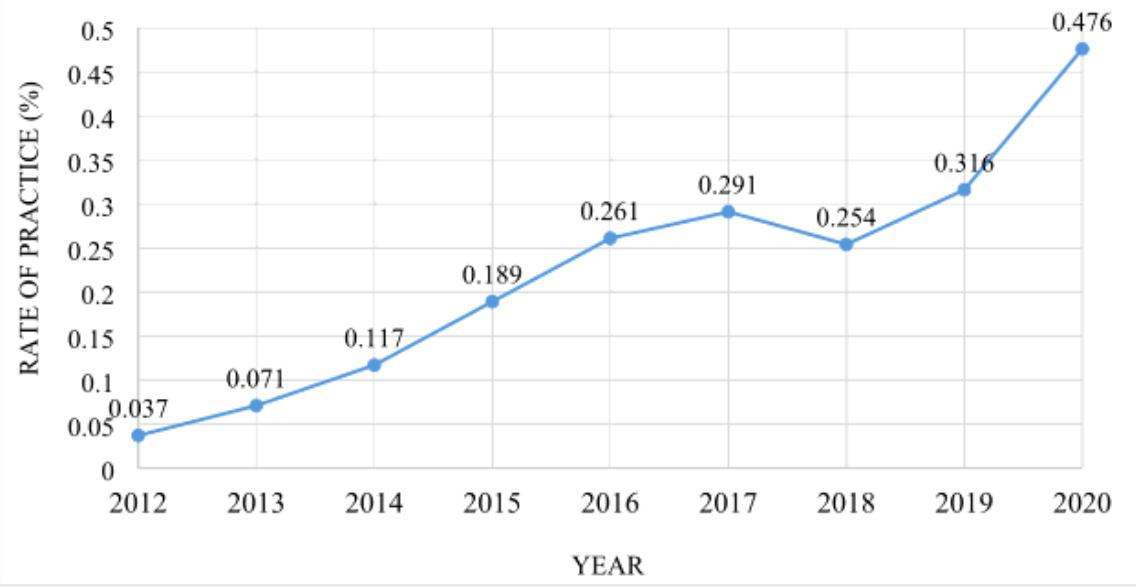

\section{Figure 1}

Trends of homebirth practices by year in Hungary (2012-2020)

BIRTHWEIGHT PERCENTILES BY PLACE OF BIRTHS

IN HUNGARY (2012-2020)

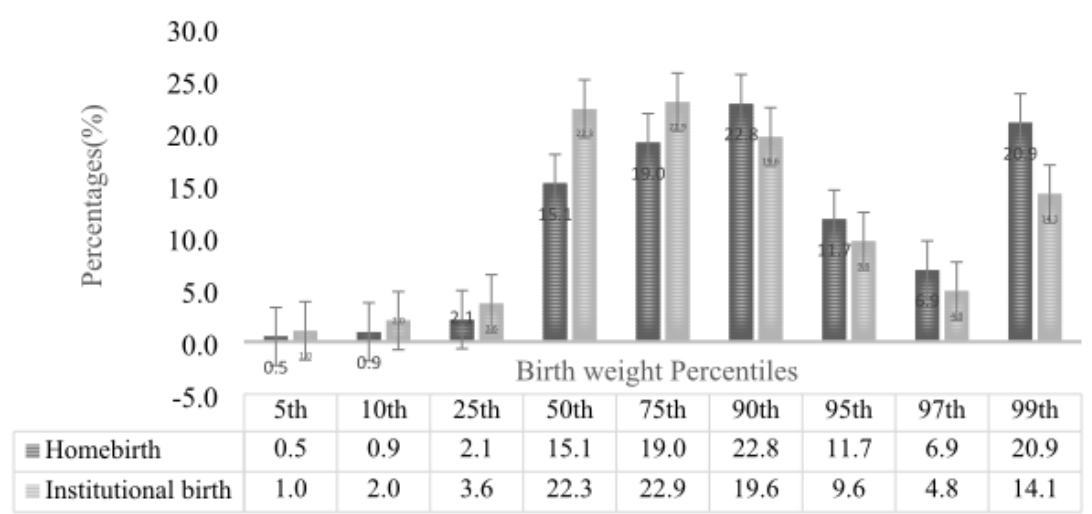

Figure 2

Birth weight percentiles by place of births in Hungary (2012-2020) 
NUMBER OF OCCURENCES OF DELIVERIES AT

HOME AND PROPORTIONS OF HOSPITALIZED

CASES

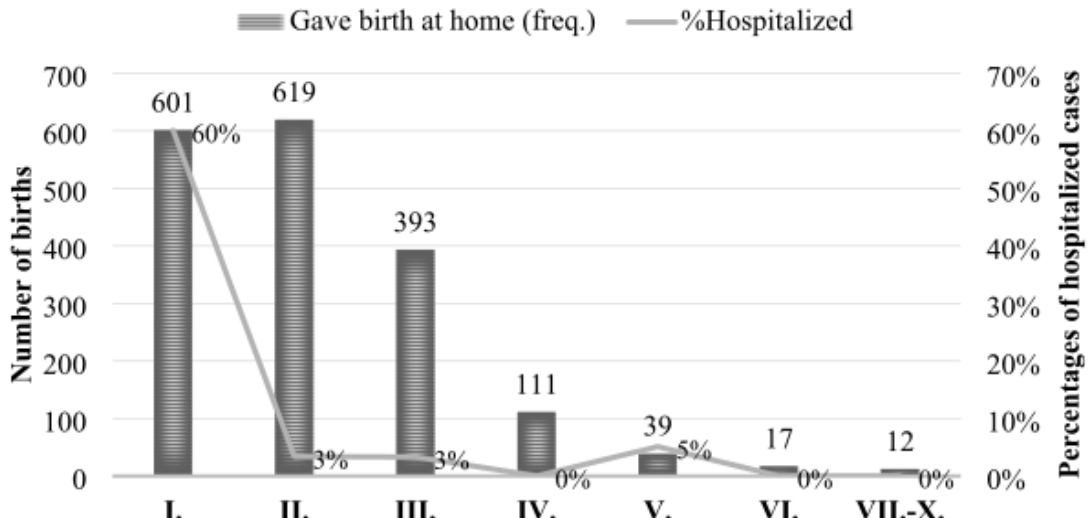

I.

II.

III.

IV.

V.

VI. VII.-X.

Number of homebirth occurrences

Figure 3

Number of occurrences a female delivered at home and proportion of hospitalized cases (2012-2020) 